two fusion points and vary also according to the sensitiveness of the skin: thus a dry skin is less sensitive than one kept moist and supple by a thin film of vaseline. Moreover, although the curves obtained by plotting $D$ against $\log P$ are straight lines, they show a change of slope at a certain value of $P$, in an opposite direction in the case of the two fusion points, so that they finally intersect. This change of slope occurs also with visual and auditory sensations. As might be expected, fatigue decreases sensitiveness, raising the value of $D$ for a given $P$.

Perhaps the most important point, however, which emerges from this research is the discovery of the opposite process-an enhancement of the tactile sensation, either by fatigue of an adjacent area, or by very light previous stimulation of the actual area under study; it is seen also in a fatigued area when the fatigue has passed off. The process appears to be a reflex effect through the central nervous system; and its existence gives an explanation of the phenomena of itching and tickling. In the former case, scratching relieves the itching, but adjacent areas become more sensitive and the process is transferred to them: this, together with the subsidence of its own fatigue, causes enhancement of the sensitiveness of the original area, and so a vicious circle is set up; in the latter case, the effect is probably due to an enhancement of sensitiveness by means of a light stimulus: a stronger stimulus fails to arouse it. The critical frequency is highest in the case of the tactile sensation, but the actual energy necessary to stimulate is greatest for this sense, being least in the case of light. Thus the effect produced by any tactile stimulus is the resultant of the two processes, a direct fatigue of the area stimulated and the reflex enhancement of its sensitiveness : the latter is only visible if the stimulus is so light that fatigue does not occur, or if time is allowed for the fatigue produced to pass away.

\section{The Liming and Chalking of Soils.}

THE second of a series of conferences arranged by the Rothamsted Experimental Station was held on Friday, May 22, when the subject discussed was the liming and chalking of land. Prof. H. E. Armstrong, vice-chairman of the Lawes Agricultural Trust, presided over a gathering of about sixty people, including landowners, farmers, county advisors and organisers, and representatives of firms interested in the supply of chalk and lime.

The morning session was occupied with papers by Dr. J. A. Voelcker, Dr. J. A. Hanley and Mr. E. M. Crowther. Dr. Voelcker dealt with his pot and field experiments at Woburn, the results of which indicate that lime exercises more benefit than the equivalent quantity of chalk. (A full account of these experiments will shortly be published in the Report of the Woburn Experimental Farm for r923-24.) Dr. Hanley described the striking effect of applications of chalk on the acid areas of Yorkshire, and Mr. Crowther explained some of the errors inherent in all laboratory methods designed to measure the "limerequirement" of acid soils. The principal difficulty is that soil acidity is made up of an "intensity " and a "quantity" factor, which, on the close analogy of ordinary acidity, may be regarded as the expression of the degree of dissociation and total titratable acidity respectively. Lime requirement methods endeavour to express these two factors by a single value, and hence to this extent are imperfect.

The afternoon session, at the suggestion of the chairman, was devoted to a discussion of the present economic position of liming and chalking, as the urgent need for this operation on large areas of land is obvious. Col. Fenwick gave an account of the cost of preparing lime from chalk available on his estate; this works out at Ios. per ton exclusive of interest on capital expended in building the kilns. The operation is economically possible for a large farm where chalk is obtainable on the site and ordinary farm labour available. Mr. Dampier Whetham alluded to the lasting effect of chalking and pointed out that the relative merits of lime and chalk should be carefully considered before any extensive national developments are planned, in order to decide whether available capital should be used for erecting lime-kilns or chalk-grinding mills. This point was also emphasised by later speakers. Mr. Garner, of the Hertfordshire Farm Institute, said that in the case of the large areas of land dangerously near the border line of acidity, he recommended one ton of lime per acre once in a rotation. The cost of this spread over four or five years is not serious. Some discussion arose as to the best time in the rotation for application of lime, and although there were individual preferences, it appeared that any crop was suitable with the obvious exception of potatoes.

Sir John Russell, in winding up the discussion, suggested that the immediate problems were: (I) to decide between the relative merits of lime and chalk; (2) to prepare a survey of areas needing treatment; (3) to supplement the geological maps by a survey of the relative accessibility of known deposits ; (4) to decide what percentage of magnesium could be safely allowed in the deposits of magnesium limestone should these be used. The conference expressed its approval of these suggestions and was unanimously of opinion that this urgent problem of soil acidity should be dealt with on a national basis, and that some form of loan or financial assistance to farmers is imperative if remedial measures are to be carried out under present economic conditions.

\section{University and Educational Intelligence.}

CAMBridge.-Mrs. Marshall has offered to the University, towards the expenses of the Marshall Library in Economics, the sum of $250 l$. annually during her lifetime, the profits from the sale of the "Memorials of Alfred Marshall," which is about to be published, and a further sum dependent upon the profits from the sale of her husband's books.

The director of the Rockefeller Foundation has written an important letter to the University, giving to the University freedom to modify the plans with regard to the school of pathology which the Foundation recently endowed, should changed conditions or subsequent experience prove the modifications to be desirable. The terms in which this wise provision is made are worth recording; a clause is added to the deed of gift: " with the understanding that the University will in good faith give a full and complete trial over a period of years to its plan for which these funds are contributed but will not be obligated to continue in perpetuity any particular type of organisation or method of instruction."

The Vice-Chancellor announces the resignation on December $3 \mathrm{I}$ next of Dr. J. N. Keynes, Pembroke College, from the office of Registrary of the University.

Mr. V. C. Robinson, Gonville and Caius College, has been appointed assistant to the Superintendent of the Museum of Zoology.

The Goldsmith's Company has announced that it is prepared to offer certain senior studentships to the total value of $750 l$. a year for post-graduate study.

EDINBURGH.-At the meeting of the University Court on Monday, May 18 , the resignation was

NO. 2900 , VOL. I I 5$]$ 